\title{
JOHANNES VAN DER PLICHT DECORATED BY KING OF NETHERLANDS
}

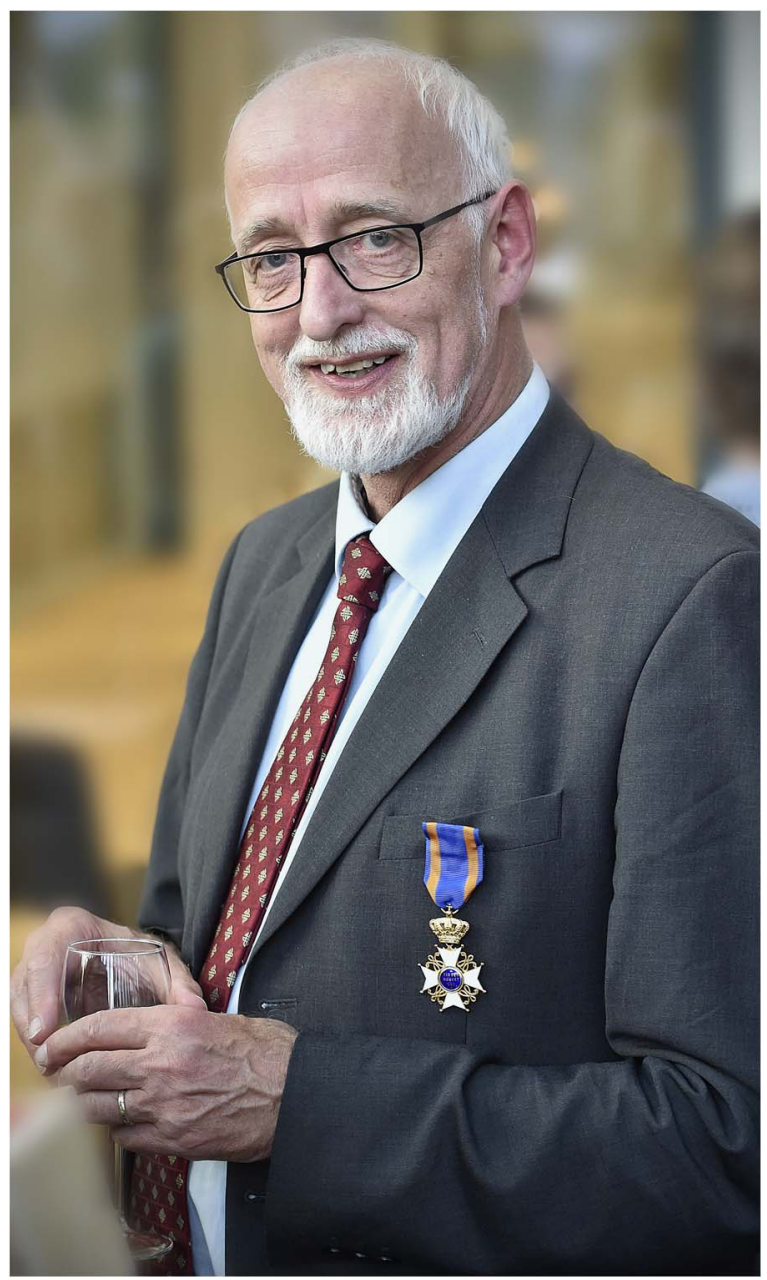

The editors of Radiocarbon would like to congratulate editorial board member Prof. Johannes (Hans) van der Plicht of the University of Groningen in The Netherlands. Upon his retirement in October 2017, he was presented with a royal decoration. Prof. van der Plicht has been appointed Knight of the Order of the Dutch Lion. 